\title{
Inhibition of phenolsulphotransferase by salicylic acid: a possible mechanism by which aspirin may reduce carcinogenesis
}

\author{
R M Harris, R J Hawker, M J S Langman, S Singh, R H Waring
}

\begin{abstract}
Background-Recent epidemiological evidence has shown that chronic use of aspirin decreases susceptibility to bowel cancer. Animal studies have shown that sulphotransferase inhibitors coadministered with sulphation activated carcinogens dramatically reduce the incidence of cancer.
\end{abstract}

Aims-To investigate the effect of the main aspirin breakdown product, salicylic acid, on the $P$ and $M$ isoforms of phenolsulphotransferase from human platelets and colonic mucosa.

Methods-Platelets were obtained from healthy blood donors and isolated within 24 hours after donation. Samples of colonic mucosa were obtained at resection for non-malignant disease. Phenolsulphotransferase activity was measured in cellular homogenates using a standard radiolabelling assay.

Results-Salicylic acid consistently and selectively inhibited the $P$ form of phenolsulphotransferase at subtherapeutic concentrations in both tissue samples. A $50 \%$ inhibition of sulphation by the $P$ phenolsulphotransferase occurred at salicylic acid concentrations of about 40 and $130 \mu M$ in platelets and bowel mucosa respectively. $M$ phenolsulphotransferase was virtually unaffected by salicylic acid up to a concentration of $1.5 \mathrm{mM}$ (the therapeutic plasma concentration for salicylates when treating rheumatoid arthritis is about 1-2 $\mathrm{mM}$ ).

School of

Biochemistry,

The University of

Birmingham,

Edgbaston,

Birmingham B15 2TT,

UK

R M Harris

R H Waring

School of Medicine,

The University of

Birmingham

M J S Langman

$\mathrm{S}$ Singh

National Blood

Service, Birmingham

R J Hawker

Correspondence to:

Dr Waring.

Accepted for publication 9 October 1997 rapidly absorbed by passive diffusion from absorbed by passive diffusion from the stomach and small intestine. The plasma concentration occurs about 25 minutes after taking the drug in soluble form. ${ }^{34}$ Once absorbed aspirin has a half life of about 20 minutes regardless of the initial dose. ${ }^{4}$ Nonspecific esterases found in the plasma, liver, and other tissues rapidly deacetylate aspirin to release salicylic acid. The latter may undergo hydroxylation, but is more commonly conjugated with either glucuronic acid or glycine. ${ }^{2}$ These conjugation pathways are saturable and the half life of salicylic acid can vary from about 2.4 to 19 hours depending on the dose. ${ }^{1}$ Although loss of the acetyl group lowers the negative logarithm of the acidic dissociation constant $\left(\mathrm{pK}_{\mathrm{a}}\right)$ of the carboxyl group from 3.5 in aspirin to 3.0 in salicylic acid, neither compound is completely ionised at physiological $\mathrm{pH} .^{2}$ Since aspirin is absorbed by passive diffusion from the alkaline small intestine ${ }^{56}$ it is likely that salicylic acid can cross cell membranes in a similar fashion. This would appear to be confirmed by experiments with cell cultures $^{7}$ and would enable an equilibrium to be maintained between the plasma and cytosolic compartments.

There is a considerable body of evidence to suggest that regular use of aspirin and other non-steroidal anti-inflammatory drugs (NSAIDs) may slow the development of malignancy in colorectal cancer..$^{8-10}$ Current theories have concentrated on the effects of these drugs on prostaglandin synthesis and the inflammatory response, ${ }^{11}$ but work by Rao and Duffel in 1991 showed that salicylic acid, the initial breakdown product of aspirin, is a potent inhibitor of aryl sulphotransferase IV (AST IV) in the rat. ${ }^{12}$ Other studies by Boberg et $a l^{13}$ and Tsutsumi et $a l^{14}$ have shown that sulphotransferase inhibitors dramatically reduce the potency of sulphation activated carcinogens in both mice and hamsters. AST IV is the rat equivalent of the human phenolsulphotransferase (PST) enzymes which catalyse the sulphate conjugation of xenobiotic compounds, neurotransmitters, and drugs. PST is cytosolic and exists in two forms, P-PST which selectively sulphates micromolar concentrations of phenols and M-PST which is similarly selective for aromatic amines. This distinction is not absolute and the enzymes will metabolise substrates from either group at high (millimolar) concentrations. Sulphate conjugation occurs via the transfer of a sulphate group from 3'-phosphoadenosine-5'phosphosulphate (PAPS) onto the target molecule..$^{15}$ Phenolsulphotransferases are found throughout the body, but the bowel, liver, and platelets are known to contain particularly high activities. The total capacity of the body to sulphate compounds is not large as only small 
quantities of PAPS are available. ${ }^{16}$ However, in tissues containing high levels of PST, it may be possible for metabolites to achieve dangerous concentrations.

The aim of this study was to examine the effect of salicylic acid in vitro on human M-PST and P-PST. Platelets have been widely used as a representative source of both of these enzymes and could be obtained in the relatively large quantities necessary for the initial experiments. Once an effect had been established it was confirmed in a smaller number of samples of non-cancerous colonic mucosa.

\section{Methods}

TISSUE PREPARATION

Platelets were obtained from the remnant buffy coats of 12 individual anticoagulated whole blood donations produced by centrifugation and the separation of plasma and red cells. It was assumed that, as blood donors, these people would represent a fairly random sample of healthy members of the general population. Six age matched buffy coats were selected from each sex (mean age (SD): males, 47 years 4 months (11 years 11 months); females, 46 years 6 months (12 years)), centrifuged at 200 $g$ for 15 minutes, and the platelet rich plasma collected. The platelets were then sedimented by centrifugation at $8000 \mathrm{~g}$ for five minutes at $4^{\circ} \mathrm{C}$, washed three times in TES buffered saline (10 $\mathrm{mM} \quad \mathrm{N}$-tris(hydroxymethyl)methyl-2aminoethanesulphonic acid (TES), $4 \mathrm{mM}$ EDTA, $0.9 \%$ sodium chloride, $\mathrm{pH} 7.0$ ) and resuspended in $4 \mathrm{ml}$ storage buffer $(10 \mathrm{mM}$ TES, $0.25 \mathrm{M}$ sucrose, $2 \mathrm{mM}$ 2-mercaptoethanol, $\mathrm{pH}$ 7.0). The platelets were ruptured by ultrasonication (MSE 5-63 ultrasonic homogeniser, three 10 second bursts at $1.6 \mathrm{~A}$ ) and the homogenate was frozen in $1 \mathrm{ml}$ aliquots at $-20^{\circ} \mathrm{C}$.

Normal mucosa was obtained from sigmoid colon resections taken from three patients with different disorders: a 45 year old female with

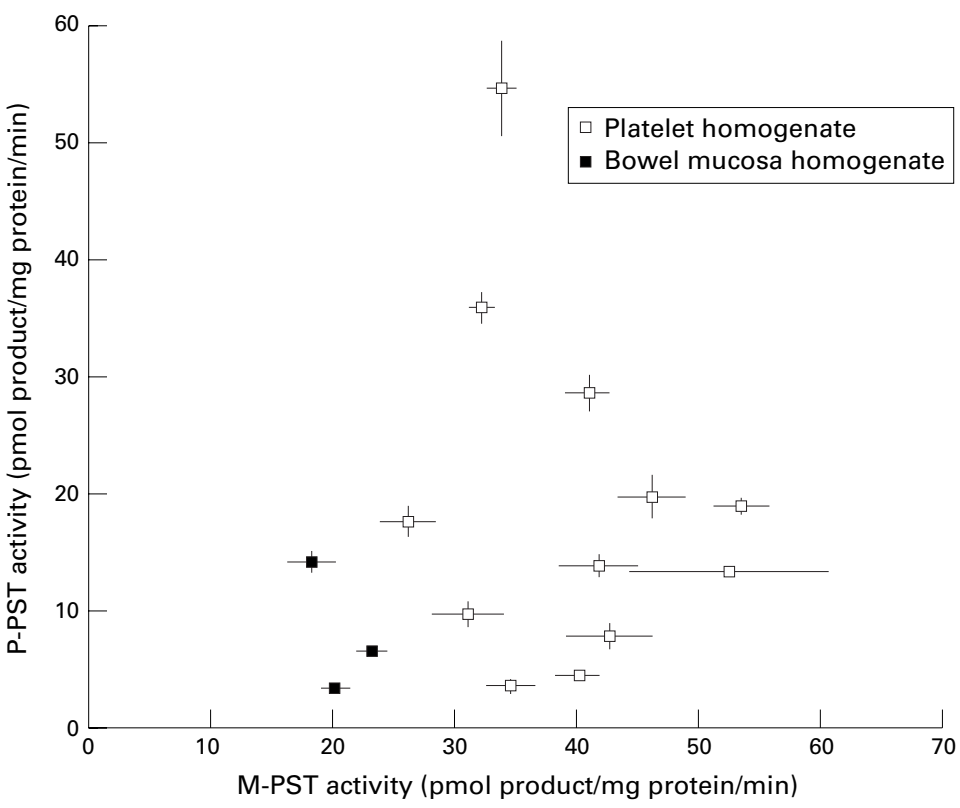

Figure 1 Basal activity of M-PST and P-PST in platelet and bowel mucosa homogenates. The points show mean (SD) of triplicate assays. pelvic exenteration for advanced cervical cancer; a 47 year old female with constipation; and a 72 year old male with colitis. About $0.25 \mathrm{~g}$ tissue was homogenised in $1.5 \mathrm{ml}$ ice cold storage buffer, and a $200 \mu \mathrm{l}$ portion was removed for activity screening. The homogenates were stored at $-20^{\circ} \mathrm{C}$ in $1.5 \mathrm{ml}$ microcentrifuge tubes. Prior to use, the samples were thawed and the tubes suspended in a $250 \mathrm{ml}$ beaker full of ice and water. The probe from an MSE 5-63 ultrasonic homogeniser was immersed in the water to a depth of about $25 \mathrm{~mm}$ and the samples subjected to five 15 second bursts of indirect ultrasonication at $1.6 \mathrm{~A}$.

PHENOLSULPHOTRANSFERASE ASSAY

Sulphotransferase activity was measured using a method based on that of Foldes and Meek ${ }^{17}$ as modified by Anderson and Weinshilboum. ${ }^{18}$ Tissue homogenate $(20 \mu \mathrm{l})$ was incubated with 6.7 $\mu \mathrm{M}$ of the standard test substrates 4-nitrophenol (to measure P-PST activity) or dopamine (to measure M-PST activity), $6.7 \mu \mathrm{M}^{35} \mathrm{~S}$ labelled PAPS, and salicylic acid (as required) in a total volume of $150 \mu \mathrm{l}$ of $20 \mathrm{mM}$ TES buffer adjusted to $\mathrm{pH} 7.0$ at $37^{\circ} \mathrm{C}$. After 40 minutes incubation at $37^{\circ} \mathrm{C}$, the reaction was stopped by adding $0.1 \mathrm{M}$ barium acetate $(200 \mu \mathrm{l})$. Any unreacted PAPS, free sulphate, or protein was precipitated by two additions of $0.1 \mathrm{M}$ barium hydroxide $(200 \mu \mathrm{l})$ followed by $0.1 \mathrm{M}$ zinc sulphate $(200 \mu \mathrm{l})$. Control assays showed that $99.5(0.06) \% \quad(n=36$ observations in triplicate, mean (SD)) of free PAPS was precipitated by this procedure. The loss of phenolic sulphates is very small ${ }^{17}$ and the assay has been found to be reliable and reproducible in this laboratory. ${ }^{19}$ After the precipitation steps, the radioactivity was measured in $500 \mu \mathrm{l}$ supernatant following centrifugation at 11500 $g$ for three minutes, and all assays were performed in triplicate.

Protein concentration was determined by the method of Bradford using $1 \mathrm{mg} / \mathrm{ml}$ bovine serum albumin in storage buffer as the standard. ${ }^{20}$

\section{Results}

PST activity, like that of most other drug metabolising enzymes, can vary by a factor of 10 in the general population. A portion of each tissue homogenate was therefore screened for activity and the results used to calculate a dilution factor for each sample such that less than $10 \%$ of the substrates would be metabolised in subsequent experiments. Although the numbers were limited, a particularly large variation in P-PST activity was seen among the platelet samples with no apparent correlation to M-PST activity (fig 1). However, despite the wide range in basal activities, the results from the inhibition studies (fig 2) clearly show the consistency and selectivity with which salicylic acid inhibits P-PST and not M-PST. It can be seen that $50 \%$ inhibition occurs at salicylic acid concentrations of about $40 \mu \mathrm{M}$ and $130 \mu \mathrm{M}$ for platelet and mucosal P-PST respectively. This difference may be due to protein binding as protein concentrations of the mucosal 

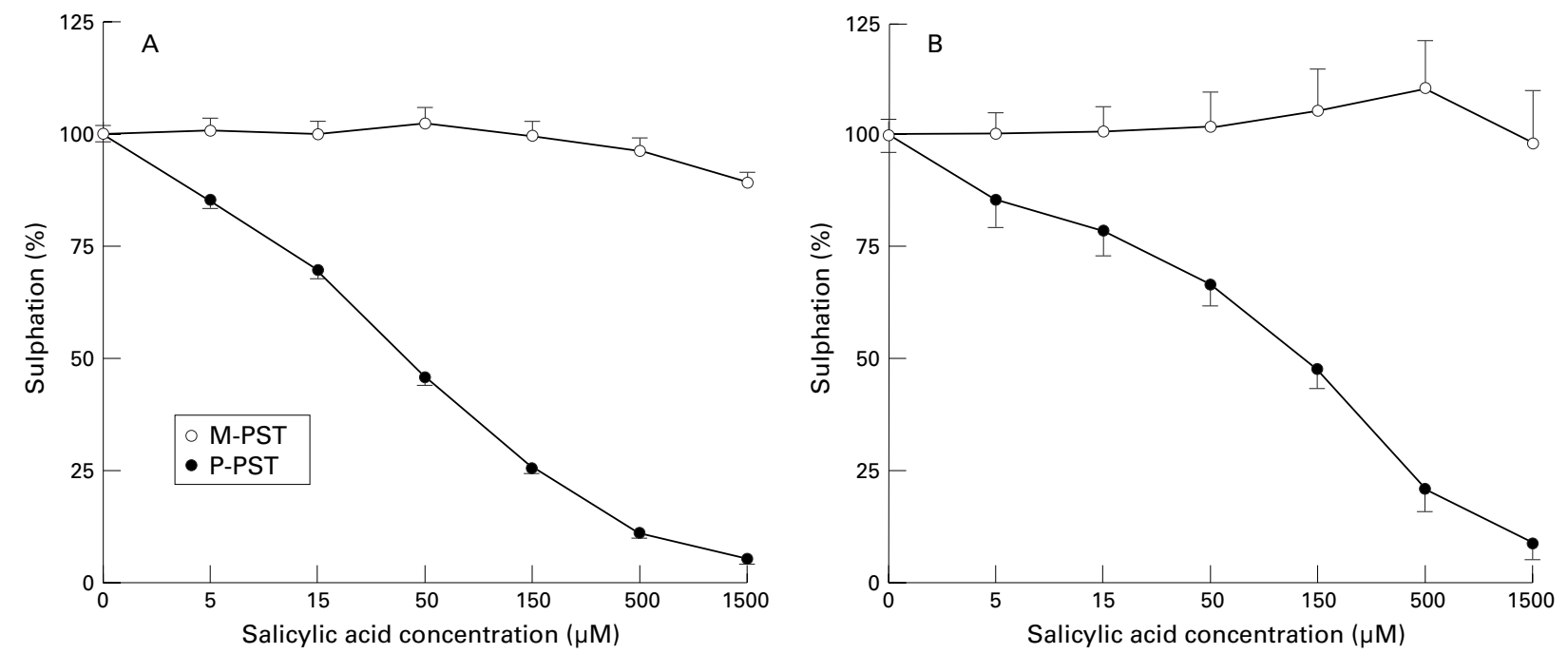

Figure 2 The effect of salicylic acid on M-PST and P-PST in (A) platelet and (B) bowel mucosa homogenates. The points show mean (SEM) values (platelet $n=12$, mucosa $n=3$ ); all samples were assayed in triplicate.

homogenates was about threefold greater than that of the platelet homogenate (12.3 (4.5) $\mathrm{mg} / \mathrm{ml}$ versus $4.0(1.1) \mathrm{mg} / \mathrm{ml})$.

\section{Discussion}

With increasing longevity, the evolution of sulphation as a detoxification process has become a double edged sword. While it undoubtedly performs a vital function in scavenging low concentrations of endogenous and exogenous toxins from the body, the lability of the phenolic sulphate-ester bond means that it is liable to cause the formation of electrophilic free radicals. These react chemically with DNA which may cause mutations leading to neoplasia. ${ }^{16}$ PAPS has a limited availability in vivo which may be an evolutionary feature that minimises cytotoxic damage from sulphation.

The cooking process is known to form a variety of mutagenic compounds, including polyaromatic hydrocarbons and heterocyclic amines, particularly if the food becomes charred, for example, when grilled or barbecued. Several polyaromatic hydrocarbons have been shown to be activated by hydroxylation to phenols followed by sulphation via P-PST to the final mutagenic form. ${ }^{21}$ P-PST has also been found to be responsible for the activation of heterocyclic amines by $\mathrm{N}$-sulphation, for example, the bladder carcinogen 2-naphthylamine, ${ }^{22}$ and a variety of carcinogenic N-hydroxy arylamines and N-hydroxy heterocyclic amines. ${ }^{23}$ Potentially, therefore, the inhibition of P-PST would block one route of activation for both main groups of carcinogen found in food. Although the values for P-PST activity varied quite widely between individuals (fig 1), suggesting that different isoforms may have been present, inhibition was constant across the range. It is not clear why P-PST and not M-PST is affected by salicylate inhibition. Although the $M$ and $P$ isoforms have very similar primary sequences, ${ }^{24}$ the differing substrate specificity ${ }^{16}$ suggests variations in tertiary structures. Flavonoids also inhibit P-PST activity, kinetic studies suggesting that non- competitive inhibition may be involved, ${ }^{25}$ and P-PST may therefore have a phenolic binding region at or near the active site.

Rainsford has shown that in rats the peak concentration of salicylate in intestinal mucosa is in excess of $2 \mathrm{mM}$ following a single dose of aspirin of $200 \mathrm{mg} / \mathrm{kg} .{ }^{26}$ Given that a standard human dose for headache relief is $10-15 \mathrm{mg} / \mathrm{kg}$ it would not be unreasonable to assume a peak mucosal concentration of 100-150 $\mu \mathrm{M}$. Our results suggest that this would inhibit P-PST by about $50 \%$, and as salicylate has a half life of about 2.5 hours this effect would remain significant for a considerable period of time. ${ }^{1}$ Pharmacokinetic studies in man suggest that even a single tablet will cause significant inhibition of platelet P-PST lasting for several hours. ${ }^{12}$ Epidemiological evidence suggests that aspirin may only be protective when taken in doses of $300 \mathrm{mg}$ daily, ${ }^{27}$ which are considerably higher than those now being increasingly used in cardiovascular prophylaxis and which are necessary to inhibit platelet cyclooxygenase. At this dosage salicylate derived from aspirin is likely to be present in sufficient concentrations to decrease sulphation significantly in the gut, so reducing the build up of metabolites and thus lessening the risk of triggering neoplastic growth.

This work was supported by a grant from the World Cancer Research Fund.

1 Levy G. Pharmacokinetics of salicylate in man. Drug Metab Rev 1979;9:3-19.

2 Needs CJ, Brooks PM. Clinical pharmacokinetics of the salicylates. Clin Pharmacokinet 1985;10:164-77.

3 Morgan AM, Truitt EB. Evaluation of acetylsalicylic acid esterase in aspirin metabolism. F Pharm Sci 1965;54:16406.

4 Rowland M, Riegelman S, Harris PA, Sholkoff SD. Absorption kinetics of aspirin in man following oral administration of an aqueous solution. F Pharm Sci 1972;61:379-85.

5 Hogben CAM, Tocco DJ, Brodie BB, Schanker LS. On the mechanism of intestinal absorption of drugs. $\mathcal{F}$ Pharmacol Exp Ther 1959;125:275-81.

6 Schanker LS, Tocco DJ, Brodie BB, Hogben CAM. Absorption of drugs from the rat small intestine. F Pharmacol Exp Ther 1958;123:81-8.

7 Elder DJE, Hague A, Hicks DJ, Paraskeva C. Differential growth inhibition by the aspirin metabolite salicylate in
grow human colorectal tumor cell lines: enhanced apoptosis in carcinoma and in vitro-transformed adenoma relative to adenoma cell lines. Cancer Res 1996;56:2273-6. 
8 Rosenberg L, Palmer JR, Zauber AG, Warshauer ME, Stolley PD, Shapiro S. A hypothesis: nonsteroidal antiinflammatory drugs reduce the incidence

9 Thun MJ, Namboodiri MM, Heath CW. Aspirin use and reduced risk of fatal colon cancer. N Engl f Med 1991;325: 1593-6.

10 Greenberg ER, Baron JA, Freeman DH, Mandel JS, Haile R. Reduced risk of large-bowel adenomas among aspirin users. F Natl Cancer Inst 1991;85:912-6.

11 Marnett LJ. Aspirin and the potential role of prostaglandins in colon cancer. Cancer Res 1992;52:5575-89.

12 Rao SI, Duffel MW. Inhibition of aryl sulfotransferase by carboxylic acids. Drug Metab Dispos 1991;19:543-5.

13 Boberg EW, Miller EC, Miller JA, Poland A, Liem A. Strong evidence from studies with brachymorphic mice and pentachlorophenol: that 1 -sulfooxysafrole is the major ultihydroxysafrole in mouse liver. Cancer Res 1983;43:516373.

14 Tsutsumi M, Noguchi O, Okita S, et al. Inhibitory effects of sulfation inhibitors on initiation of pancreatic ductal carcinogenesis by $N$-nitrosobis (2-oxopropyl)amine in hamsters. Carcinogenesis 1995;16:457-9.

15 Weinshilboum R. Sulfotransferase pharmacogenetics. In Kalow W, ed. Pharmacogenetics of drug metabolism. New York: Pergamon Press, 1992:227-42.

16 Coughtrie MWH. Sulphation catalysed by the human cytosolic sulphotransferases - chemical defence or molecular terrorism? Hum Expl Toxicol 1996;15:547-55. 17 Foldes A, Meek JL. Rat brain phenolsulfotransferaseActa 1973;327:365-74.
18 Anderson RJ, Weinshilboum RM. Phenolsulphotransferase in human tissue: radiochemical enzymatic assay and biochemical properties. Clinica Chimica 80 .

19 Harris RM, Waring RH. Dietary modulation of human platelet phenolsulphotransferase activity. Xenobiotica 1996; 26:1241-7.

20 Bradford MM. A rapid and sensitive method for the quantification of microgram quantities of protein utilizing the principle of protein-dye binding. Anal Biochem 1976;72: 248-54

21 Grover PL. Pathways involved in the metabolism and activation of polycyclic hydrocarbons. Xenobiotica $1986 ; 16$ : 915-31.

22 Hernández JS, Powers SP, Weinshilboum RM. Human liver arylamine $\mathrm{n}$-sulfotransferase activity. Thermostable phenol sulfotransferase catalyzes the N-sulfation of 2-naphsulfotransferase catalyzes the N-sulfation of
thylamine. Drug Metab Dispos 1991;19:1071-9.

23 Chou H-C, Lang NP, Kadlubar FF. Metabolic activation of $\mathrm{N}$-hydroxy arylamines and N-hydroxy heterocyclic amines by human sulfotransferase(s). Cancer Res 1995;55:525-9.

24 Weinshilboum RM, Otterness DM, Aksoy IA, Wood TC, Her C, Raftogianis RB. Sulfotransferase molecular biology:

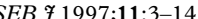

25 Ghazali RA, Waring RH, Helsby N. Metabolism of dietary flavonoids. ISSX Proceedings 1996;9:42.

26 Rainsford KD. The effects of aspirin and other non-steroid anti-inflammatory/analgesic drugs on gastro-intestinal mucus glycoprotein biosynthesis in vivo: relationship to ulcerogenic actions. Biochem Pharmacol 1978;27:877-85.

27 Giovannucci E, Egan KM, Hunter DJ, et al. Aspirin and the risk of colorectal cancer in women. $N$ Engl $f \mathrm{Med}$ 1995;333:609-14. 